\title{
Black Lives Matter in ecology and evolution
}

\author{
Prompted by the Black Lives Matter and Shutdown STEM movements, Nature Ecology \& Evolution acknowledges the \\ systemic racism in scientific research, and the part we play in this. Here we outline our commitment to fight this
} racism.

$\mathrm{T}$ his editorial was first published as a draft on 11 June 2020 , in order to solicit feedback from the community. That draft was the result of our thinking over the last few troubling weeks but specifically the result of having spent Wednesday 10th June reading and reflecting as part of \#ShutDownSTEM. We did not expect our colleagues in the wider research community, particularly our Black colleagues, to do the work of telling us what to say. It is important that we as privileged white editors shout our support for \#BlackLivesMatter, and it is even more important that we follow our words with actions. However, as editors of this journal we have a privileged platform from which to speak, and we wanted to reflect the concerns and priorities of the diverse members of the community. In particular, we wanted to listen with humility. That is why we took the unusual step of publishing a draft for others to comment on if they so wished. This final published version reflects the feedback we received, although we could not accommodate all comments, especially those that contradicted each other, and the final version is ultimately the word of the editors. The original draft remains on our community site, along with the feedback that was posted publically (although much of it was sent privately). We sincerely thank everyone who took the time to comment.

We are a team of six full-time professional editors (one on parental leave who was not involved in writing this), all of whom are white. We are the only editors to have worked on this journal in its relatively short life. We believe that the whole scientific and publishing worlds need to acknowledge and take drastic actions to correct the systemic racism that discriminates against Black researchers.

It is tragic that we are saying these things now, after the horrific deaths of George Floyd, Breonna Taylor, Ahmaud Arbery and countless others both in the United States and the rest of the world (for example Stephen Lawrence in the United Kingdom and João Pedro Matos Pinto in Brazil). We should have been loudly challenging racism in all aspects of our lives, with words and deeds, for decades. It is not as if we were not well aware of the suffering of our Black neighbours, and the way in which the entire structure of society is stacked against them. Our failure up to this point is shaming. It should also be clearly recognized that this is not just an American problem. Almost all countries, and particularly those European countries with a long history of colonial exploitation, are riddled with structural racism. The recent and belated removal of a few racist statues in the United Kingdom and Belgium is just one headline-grabbing indication of this.

These huge failings in society are mirrored in science, and in some aspects are even more acute. We, the ecology and evolution community, now need to act, as individual members of society, as researchers and teachers; and Nature Ecology \& Evolution needs to act as a journal.

As individuals, those of us who do not experience racism directly need to be active allies. We should offer practical and financial help, but we should not expect or hog the limelight. We should be loud when it helps to champion those with lived experience, but defer to their voices. There is useful guidance in places such as here (US-focused) and here (UK-focused). We should be constantly asking questions about diversity and inclusion in every project, event or day-to-day interaction we are involved with, and should not leave doing so as another burden for our Black friends and colleagues (see here for an example of this burden in academia). We should be actively questioning our own motives and biases in all our decision-making. We should write to political representatives, institutions and corporations to challenge them to be actively anti-racist.

As scientists, we have choices about who we hire, who we collaborate with, who we cite and what we teach. Admitting students and recruiting junior researchers and faculty is perhaps where the biggest failing of academic institutions occurs. It is not acceptable to fall back on the assertion that race does not exist genetically, that we are not biased, or that we are 'colour-blind'. Race exists as a very real social construct. We need to reach out beyond those who naturally apply for positions as the end result of systemically racist social and educational structures that consistently disadvantage minorities. When we collaborate and when we cite, we should actively look for researchers outside the prestigious white-dominated institutions that are so often our first port of call. And we should ensure that collaboration leads to authorship on publications rather than mere acknowledgement. Those researchers who are involved in funding decisions need to be particularly strong champions of equitable distribution that attempts to combat the burden that non-white researchers will have shouldered in order to get to the equivalent career stage as white researchers.

When we teach ecology and evolution, we do not teach in a historical vacuum. We constantly reference the individuals who developed particular concepts and we should make sure we highlight the contributions of Black scientists (for example, here, here and here). We also need to confront the racist history of most fields of science and undertake a programme of decolonization (see examples from anthropology, genetics, ecology and conservation). And we need to pay specific attention to the mentoring needs of students and early-career researchers from underrepresented groups, and take steps to counter any financial burdens they may be experiencing.

Finally, researchers need to acknowledge that as well as structural biases, there are repeated incidences of active racism in science, and we need to call out the individuals involved and take action against them. We need to ensure that ecology and evolution research is a career in which Black scientists feel safe and welcome.

As a journal, we pledge to take action. This is not the place for special pleadings on what we have already done, so we note it only to illustrate our failings. We have taken action to increase the diversity of our authors and reviewers, but this has focused predominantly on gender (and that only in a binary way), and secondarily on geography. We have not taken specific action on race, mistakenly thinking this would come about as an intersectional by-product. White editors must confront the fact that our own biases, as well as the inadvertent ways we have contributed to systemic racism and discrimination, have most likely made success for Black authors more difficult. 
We need to take increased steps to ensure submissions from non-white authors are treated fairly. We do not currently have the set-up to document race or ethnicity of authors formally in our submission system, and this is something we will advocate for within the wider structure of Nature Research, as it will allow us to hold ourselves to account in a more quantitative way. As well as monitoring diversity across our published content and rejected submissions, such data could help us to start to explore whether certain fields that are particularly white-dominated are overrepresented in our pages. In the meantime, as an imperfect solution, we now ask authors, if they wish, to self-identify in their cover letters. We undertake to add an extra layer of editorial oversight to such submissions and will endeavour to provide additional guidance to those that are rejected without peer review, as we are aware that not all authors have access to equivalent networks of peer advice. It should be noted that the information in cover letters does not get sent to peer reviewers, and authors can also opt for double-blind peer review. The editors commit to undertake implicit bias training once a year, and we will encourage reviewers to do the same.

We will increase our effort to represent Black voices in our commissioned content and publish more content that discusses diversity. We will use our Q\&A section exclusively to showcase underrepresented groups at all career stages, and would welcome interested researchers contacting us to take part. We will set up a channel on our community site to discuss diversity and inclusion, and particularly encourage lab groups to discuss topics related to race and report their findings on that channel. We will direct our outreach activities towards institutes that are not white-dominated, and actively look for opportunities to talk to minority groups and individuals about publishing in Nature journals and editorial careers. We will not take part in all-white (or all-male) panel discussions, and we will only attend meetings that have a robust code of conduct. We will add further checks to our editorial processes for appropriate language relating to race in our published content, drawing on the wider expertise within Springer Nature and beyond. As a small professional editorial team, with very limited turnover (and no external editorial board), there are limits to what we can achieve alone. Therefore, we will use our influence to push for changes within Springer Nature and the wider publishing industry, such as formal anti-racist policies to empower those who speak out, proactive hiring efforts that are not predicated on the types of experience that white people are more likely to have had access to, and the prioritization of underrepresented groups when allocating funding and sponsorship.

Finally, we undertake to continue to fight racism and discriminatory structures as an ongoing process, and we will report on our progress in future editorials.

Published online: 23 June 2020

https://doi.org/10.1038/s41559-020-1250-2 